\title{
Modelling and Simulation of Target Temperature Effect on Eddy Current Sensing: Toward Concurrent Displacement and Temperature Estimation
}

\author{
Darko Vyroubal ${ }^{1}$, Vedran Vyroubal $^{2}$, Adam Stančić \\ Professor, Karlovac University of Applied Sciences, Karlovac, Croatia ${ }^{1}$ \\ Lecturer, Karlovac University of Applied Sciences, Karlovac, Croatia ${ }^{2,3}$
}

\begin{abstract}
Target temperature effect on eddy current displacement sensing is modelled, analysed and evaluated by simulation. The equivalent target quality factor is detected as the main factor that, along with the eddy current displacement probe equivalent quality factor, determines this effect. It manifests in ambiguity of displacement measurement, as well as, masking the displacement variation by target temperature variation, and vice versa. The analysis and the simulation show that there is an optimal operating frequency for minimum sensitivity over an acceptable displacement range. The effect can be used for concurrent non-contact estimate of displacement and target temperature with acceptable error less than $5 \%$.
\end{abstract}

Keywords: Modelling and simulation, target temperature effect, eddy-current displacement sensing, displacement and temperature estimation.

\section{INTRODUCTION}

Among various approaches to improve efficiency of power turbo machinery (e.g. turbines, compressors, pumps), the reduction of clearances (e.g. rotor-to-stator, bearings, seals etc.) and displacements [1] is one of the goals in contemporary turbo machinery design trends. Measuring and monitoring the reduced clearances and displacements are vital for optimal exploitation of these machines, as well as, for preventing catastrophic failures like rotor-tostator rub, vibration caused bearing damage etc. The eddy current displacement transducers have been used successfully for this task for many decades and this method and the corresponding commercial equipment are considered to be a reliable and matured technology. However, its application has been so far limited to temperature range primarily dictated by probe technology, typically $-50^{\circ} \mathrm{C}$ to $+200^{\circ} \mathrm{C}$ [2]. New demands, like measurement of gas turbine disc axial movement and rotor trajectory in the engine core; blade tip clearance over shrouded turbine rotors [3]; bearing clearances in rocket engine cryogenic fuel pump [4] etc., push the limits of required temperature range to extremes $\left(-252^{\circ} \mathrm{C}\right.$ for a liquid hydrogen pump, well over $500^{\circ} \mathrm{C}$ for a gas or steam turbine). Furthermore, concurrent monitoring of the local hot spots (e.g. turbine blade edge etc.) would be useful in order to prevent material overheating. Development of the transducer system for such a wide temperature range is very challenging and the effect of temperature in various aspects must be analysed very carefully. So far, only the temperature effect on transducer electronics [4], [10] and the eddy current displacement probe [4], [5] have been addressed, while the target temperature effect on measurement has not been widely recognized, only noticed [5], [6] and mostly ignored.

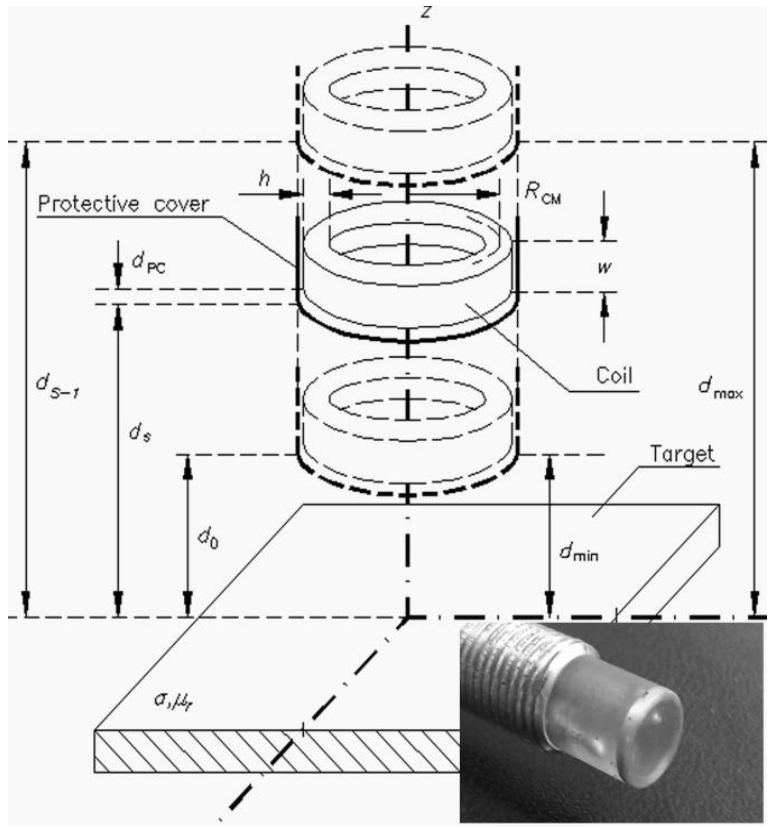

Fig. 1 Probe-target set-up, probe tip close-up view is in the inset

This paper is extension of [11]. It is organized as follows: Section II describes the probe-target model, Section III provides the analysis of the target temperature effect on eddy current sensing, Section IV reports simulation results based on model and analysis presented, Section V thoroughly analyses various methods for concurrent estimation of displacement and target temperature, Section VI presents an example of displacement and temperature estimation, while Section VII concludes this paper. 


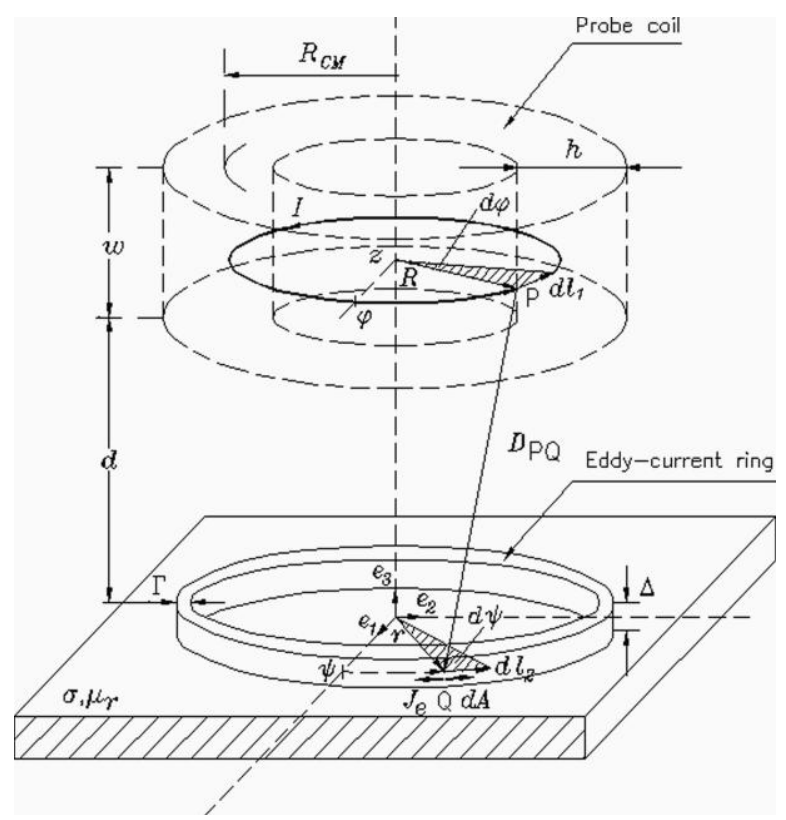

Fig. 2 Coil-target geometry for calculation of the eddy current distribution in the target

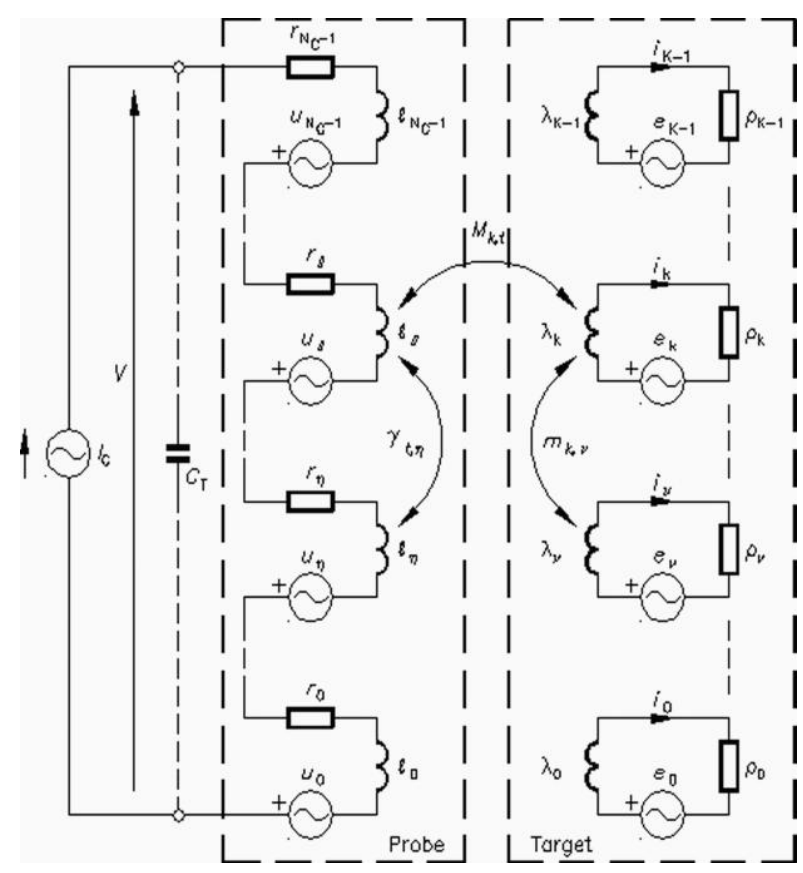

Fig. 3 Probe-target distributed equivalent circuit.

\section{PROBE-TARGET MODEL}

\section{A. Probe-target Set-up}

The only active part of the eddy current probe is a simple coil placed in the tip of the probe. The coil may have a ferromagnetic core, but usually it is coreless. In the following analysis and simulation the coil parameters are as for the probe referred to as "Probe No.2" in [8], [9], [10] (coreless, thin circular ring-shaped coil, coil mean radius $R_{C M}=3.46 \mathrm{~mm}$, winding height $h=0.92 \mathrm{~mm}$, winding width $\mathrm{w}=0.8 \mathrm{~mm}$, number of turns $\mathrm{Nc}=70, \mathrm{Cu}-$ wire diameter $0.1 \mathrm{~mm}$, inductance $\mathrm{L}_{1}=51 \square \mathrm{H}$, Qfactor $\left.\mathrm{Q}_{1}=14 @ 1 \mathrm{MHz}\right)$. The probe is placed perpendicularly to the target surface at varying displacement (Fig. 1). The inset in Fig. 1 is the close-up view of the probe tip, clearly showing the shape of the coil.

\section{B. Probe-target Equivalent circuit}

The coil turns are distributed over the coil width, w and the coil height, h (Fig. 2). Each turn carries the excitation current, Ie $\mathrm{j}^{\mathrm{j \omega t}}$ which contributes to the vector magnetic potential, $\mathbf{A}(\mathrm{r}, \psi, \mathrm{t})$ in the target, where Iis the amplitude and $\square$ is the frequency of the excitation current. The eddy current density $\mathbf{J}(r, \psi, t)$ at a point in the target is with the target conductivity $\square$ proportional to the time derivative of the vector magnetic potential at this point [9]

$$
\mathbf{J}(\mathrm{r}, \psi, \mathrm{t})=-\sigma \frac{\partial \mathbf{A}(\mathrm{r}, \psi, \mathrm{t})}{\partial \mathrm{t}}
$$

The solution for the total vector magnetic potential [9] shows that it has no radial component and that the azimuth component is independent of the azimuth at any point in the target. Therefore, the eddy currents induced in the target follow circular paths. Due to the skin-effect, eddy currents penetrate the target to the equivalent depth $\Delta$ (skin depth). For the purpose of discrete simulation, the whole target area carrying significant eddy currents is segmented into $\mathrm{K}$ rings of width $\Gamma$ and thickness $\Delta$. Each ring is characterized with its resistance and inductance which vary with the ring radius. Because there is no radial component of the induced eddy currents, each ring can be modelled as the single turn of the equivalent transformer secondary, loaded with the ring's resistance and inductance, insulated from other rings. Consequently, mutual inductances exist between each of the probe coil $\mathrm{N}_{\mathrm{C}}$ turns and each ring, as well as, between every turn of the coil and the rest of the turns, and also between every ring and the rest of the rings. Such a magnetic coupling results in the probe-target distributed equivalent circuit in Fig. 3. $\mathrm{C}_{\mathrm{T}}$ is the external capacitor added for tuning the equivalent probe impedance into resonance [9], [10]. All other parasitic capacitances are neglected in this model. It is justified, as for instance with average ring parameters $\square=1.25 \mathrm{~mm}, \mathrm{r}=3.5 \mathrm{~mm}$ [9], the ring inductance is $\square \square 23 \mathrm{nH}$ which would require parasitic capacitance of $\sim 1 \square \mathrm{F}$ to get into resonance at, say $1 \mathrm{MHz}$ ! The actual parasitic capacitance is assessed to be much smaller, therefore its omission is justified. Neglecting $\mathrm{C}_{\mathrm{T}}$ for the moment (to be included later), the total voltage across the probe terminals is derived from the distributed equivalent circuit [9]

$$
V=\left(R_{1}+j \omega L_{1}\right) I+U
$$

where $\mathrm{U}$ is the total voltage induced in coil turns coupled with the eddy currents in the target, $R_{1}$ and $L_{1}$ are the resistance and inductance of the coil far from target (no eddy currents influence)

$$
\begin{gathered}
U=\sum_{t=0}^{N_{C}-1} u_{t} \\
R_{1}=\sum_{t=0}^{N_{C}-1} r_{t} \\
L_{1}=\sum_{t=0}^{N_{C}-1} l_{t}+\sum_{\eta=0}^{N_{C}-1} \quad \sum_{\eta=0}^{N_{C}-1} \gamma_{t, \eta} t \neq \eta \\
u_{t}=j \omega \sum_{t=0}^{N_{C}-1} M_{k, t} i_{k}=-\omega^{2} \sum_{k=0}^{K-1} \quad \sum_{t=0}^{N_{C}-1} \frac{M_{k, t} e_{k}}{\rho_{k}+j \omega \lambda_{k}}
\end{gathered}
$$

Insertion of these results into (2), and application of the Ohm's law yield the equivalent probe impedance 
INTERNATIONAL JOURNAL OF INNOVATIVE RESEARCH IN ELECTRICAL, ELECTRONICS, INSTRUMENTATION AND CONTROL ENGINEERING Vol. 4, Issue 4, April 2016

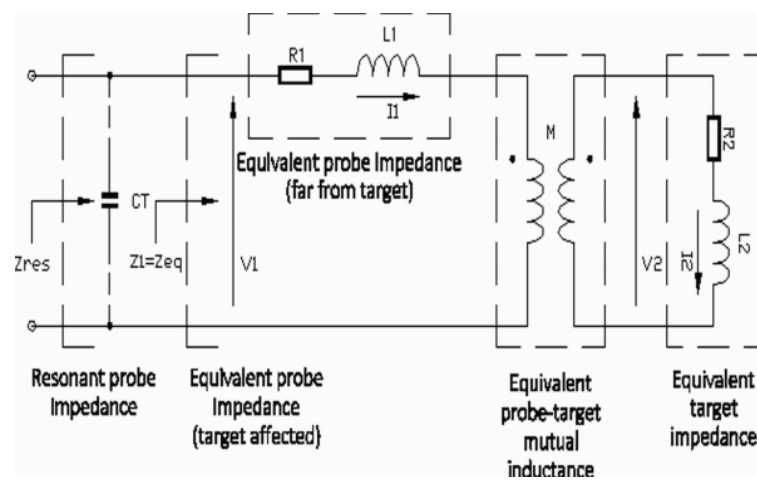

Fig. 4 Probe-target lumped equivalent circuit.

$$
\begin{aligned}
& Z_{e q}=R_{e q}+j \omega X_{e q} \\
& R_{e q}=R_{1}+\frac{\omega^{2} M^{2} R_{2}}{R_{2}^{2}+\left(\omega L_{2}\right)^{2}} \\
& X_{e q}=\omega L_{1}-\frac{\omega^{3} L_{2} M^{2}}{R_{2}^{2}+\left(\omega L_{2}\right)^{2}}
\end{aligned}
$$

where from, the probe-target lumped equivalent circuit can be derived as in Fig. 4.The equivalent impedance real and imaginary parts both consist of two components: resistance $\left(\mathrm{R}_{1}\right)$ and inductance $\left(\mathrm{L}_{1}\right)$ not dependent on mutual inductance between the probe and the target, i.e. intrinsic probe resistance and inductance far from target, and the resistance and capacitive reactance which reflect target equivalent impedance $\left(\mathrm{R}_{2}+\mathrm{j} \square \mathrm{L}_{2}\right)$ to the probe terminals via equivalent probe-target mutual inductance (M). Adding a proper valued $\mathrm{C}_{\mathrm{T}}$ parallel to the probe, tunes the probe into resonance. The resonant probe impedance is then purely resistive and equals

$$
\operatorname{Re}\left\{\mathrm{Z}_{\mathrm{eq}}\right\}=\mathrm{Z}_{\text {res }}=\frac{\mathrm{R}_{\mathrm{eq}}^{2}+\mathrm{X}_{\mathrm{eq}}^{2}}{\mathrm{R}_{\mathrm{eq}}}, \operatorname{Im}\left\{\mathrm{Z}_{\text {res }}\right\}=0
$$

The required $\mathrm{C}_{\mathrm{T}}$ reactance for resonant tuning equals

$$
\mathrm{X}_{\mathrm{T}}=-\frac{1}{\omega \mathrm{C}_{\mathrm{T}}}=-\frac{\mathrm{R}_{\mathrm{eq}}^{2}+\mathrm{X}_{\mathrm{eq}}^{2}}{\mathrm{X}_{\mathrm{eq}}}
$$

In practice, variation of $\mathrm{R}_{\mathrm{eq}}$ and $\mathrm{X}_{\mathrm{eq}}$ with displacement would require automatic resonance tuning [10].

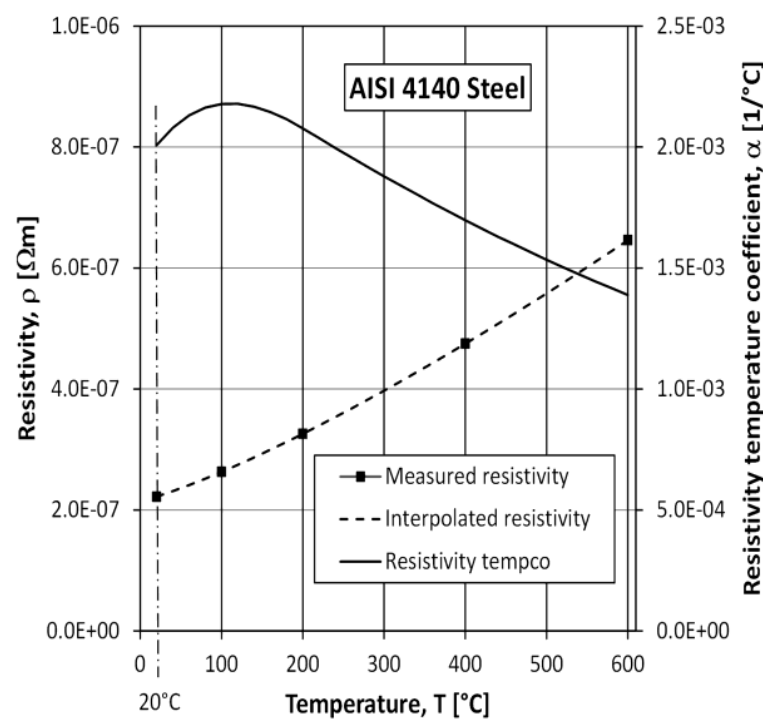

Fig. 6 apparent displacement-probe voltage transfer curves.

\section{ANALYSIS}

Combining (8) and (9) follow the quotients (12) and (13)

$$
\begin{aligned}
& Q_{\text {eq }}=\frac{X_{\text {eq }}}{R_{\text {eq }}} \\
& Q_{2}=\frac{X_{2}}{R_{2}}=\frac{\omega L_{2}}{R_{2}}=\frac{X_{1}-X_{\text {eq }}}{R_{\text {eq }}-R_{1}}
\end{aligned}
$$

which are identified as the probe equivalent quality factor $\left(\mathrm{Q}_{\mathrm{eq}}\right)$ and the target equivalent quality factor $\left(\mathrm{Q}_{2}\right)$. Parameters $\mathrm{R}_{1}, \mathrm{X}_{1}, \mathrm{R}_{\mathrm{eq}}$ and $\mathrm{Q}_{\mathrm{eq}}$ can be easily determined by measurement: $R_{1}, X_{1}$ far from target and $R_{e q}, X_{e q}$ at selected probe-to-target displacements.

Differentiation of (10) with respect to temperature yields the relative probe resonant impedance temperature sensitivity

$$
\begin{gathered}
S_{T}^{Z_{\text {res }}}=\frac{\frac{d Z_{\text {res }}}{Z_{\text {res }}}}{d T}=S_{R_{1}}^{Z_{\text {res }}} \cdot \frac{\frac{d R_{1}}{R_{1}}}{d T}+S_{X_{1}}^{Z_{\text {res }}} \cdot \frac{\frac{d X_{1}}{X_{1}}}{d T}+ \\
S_{R_{2}}^{Z_{\text {res }}} \cdot \frac{\frac{d R_{2}}{R_{2}}}{d T}+S_{X_{2}}^{Z_{\text {res }}} \cdot \frac{\frac{d X_{2}}{X_{2}}}{d T}+S_{X_{M}}^{Z_{\text {res }}} \cdot \frac{\frac{d X_{M}}{X_{M}}}{d T}
\end{gathered}
$$

where the partial sensitivities are

$$
\begin{aligned}
& S_{\mathrm{R}_{1}}^{Z_{\text {res }}}=\frac{1-Q_{\text {eq }}^{2}}{1+Q_{\text {eq }}^{2}} \cdot \frac{R_{1}}{R_{\text {eq }}} \\
& S_{X_{1}}^{Z_{\text {res }}}=\frac{2 Q_{\text {eq }}^{2}}{1+Q_{\text {eq }}^{2}} \cdot \frac{X_{1}}{X_{\text {eq }}}
\end{aligned}
$$

$S_{R_{2}}^{Z_{\text {res }}}=\left(1-\frac{R_{1}}{R_{\text {eq }}}\right) \cdot \frac{\left(1-Q_{\text {eq }}^{2}\right) \cdot\left(Q_{2}^{2}-1\right)+4 Q_{\text {eq }} \cdot Q_{2}}{\left(1+Q_{\text {eq }}^{2}\right) \cdot\left(1+Q_{2}^{2}\right)}$

$S_{X_{2}}^{Z_{\text {res }}}=2\left(1-\frac{R_{1}}{R_{\text {eq }}}\right) \cdot \frac{Q_{2} \cdot\left[Q_{2} \cdot\left(Q_{\text {eq }}^{2}-1\right)+Q_{\text {eq }} \cdot\left(Q_{2}^{2}-1\right)\right]}{\left(1+Q_{\text {eq }}^{2}\right) \cdot\left(1+Q_{2}^{2}\right)}$

$S_{X_{M}}^{Z_{\text {res }}}=2\left(1-\frac{R_{1}}{R_{\text {eq }}}\right) \cdot \frac{\left(1-Q_{\mathrm{eq}}^{2}\right) \cdot\left(1+Q_{2}^{2}\right)-2 Q_{\text {eq }} \cdot Q_{2}}{1+Q_{\text {eq }}^{2}}$.

The optimal target quality factors for cancellation of the corresponding partial sensitivities due to the target related factors follow from solving $S_{R_{2}, X_{2}, X_{M}}^{Z_{\text {res }}}=0$

$$
\begin{gathered}
{\left[Q_{2}^{O p t}\right]_{S_{R 2}^{Z} Z_{\text {res }}=0}=\frac{Q_{e q}+1}{Q_{e q}-1}} \\
{\left[Q_{2}^{O p t}\right]_{S_{X}^{Z} Z_{\text {res }}=0}=\frac{1}{Q_{e q}} \quad(16 \mathrm{a})} \\
\left.\left[Q_{2}^{O p t}\right]_{S_{X_{M}}^{Z}{ }_{\text {res }}=0}=\frac{Q_{e q} \pm \sqrt{-Q_{e q}^{4}+3 Q_{e q}^{2}-1}}{1-Q_{e q}^{2}} \cdot 16 \mathrm{c}\right)
\end{gathered}
$$

$\mathrm{Q}_{2}$ can be adjusted by selection of operating frequency, but unfortunately $\mathrm{Q}_{\mathrm{eq}}$ is also dependent on operating frequency and, as well as, on displacement. Thus, the selection of optimal frequency is also displacement sensitive what makes $S_{T}^{Z_{r e s}}=0$ impossible simultaneously for all displacements and all influencing factors.The goal is to achieve reasonably small sensitivity over the adequate displacement range. $S_{R_{1}}^{Z_{\text {res }}}$ and $S_{X_{1}}^{Z_{\text {res }}}$ are probe temperature related factors what can be treated separately and has recently been approached by several other research teams. Therefore, only the sensitivities to target temperature are analyzed in this paper. The analysis and the accompanied simulation is performed for the target made of AISI4140 steel which is the common material used for calibration of the commercial eddy current displacement transducers 
[2]. In Fig. 5 there are the resistivity and relative resistivity temperature coefficient for this material [7]. Data for low temperatures are not available, thus the analysis and simulation are restricted only to high temperatures (the most common case in practice).

Core-less probe is placed in the nonmagnetic environment (air), while the eddy current rings are, due to the very low penetration depth of the electromagnetic field, placed on the very boundary of the nonmagnetic and (possibly) magnetic environment (target). Equivalent mutual inductance $M$ and equivalent target inductance $L_{2}$ can be calculated by application of the method of magnetic imaging [9]. The result is that both $M$ and $L_{2}$ are proportional to the effective permeability and their temperature sensitivities are governed by the temperature sensitivity of this effective permeability

$$
\mu_{e f}=\frac{2 \mu_{r}}{1+\mu_{r}} \cdot \mu_{0}, \frac{\left(\frac{d \mu_{e f}}{\mu_{e f}}\right)}{d T}=\frac{1}{2\left(1+\mu_{r}\right)} \cdot \frac{\left(\frac{\mathrm{d} \mu_{\mathrm{r}}}{\mu_{\mathrm{r}}}\right)}{\mathrm{dT}}
$$

what relates to $\mathrm{X}_{\mathrm{M}}$ and $\mathrm{X}_{2}$ temperature coefficients

$$
\frac{\left(\frac{\mathrm{dX}_{\mathrm{M}}}{\mathrm{X}_{\mathrm{M}}}\right)}{\mathrm{dT}}=\frac{\left(\frac{\mathrm{dX}_{2}}{\mathrm{X}_{2}}\right)}{\mathrm{dT}} \sim \frac{\left(\frac{\mathrm{d} \mu_{\mathrm{ef}}}{\mu_{\mathrm{ef}}}\right)}{\mathrm{dT}}
$$

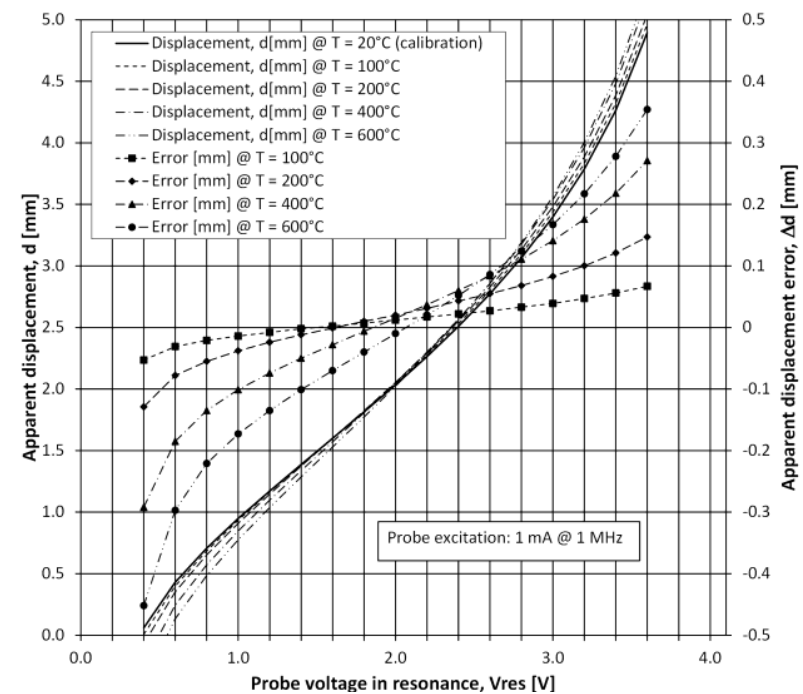

Fig. 6 apparent displacement-probe voltage transfer curves.

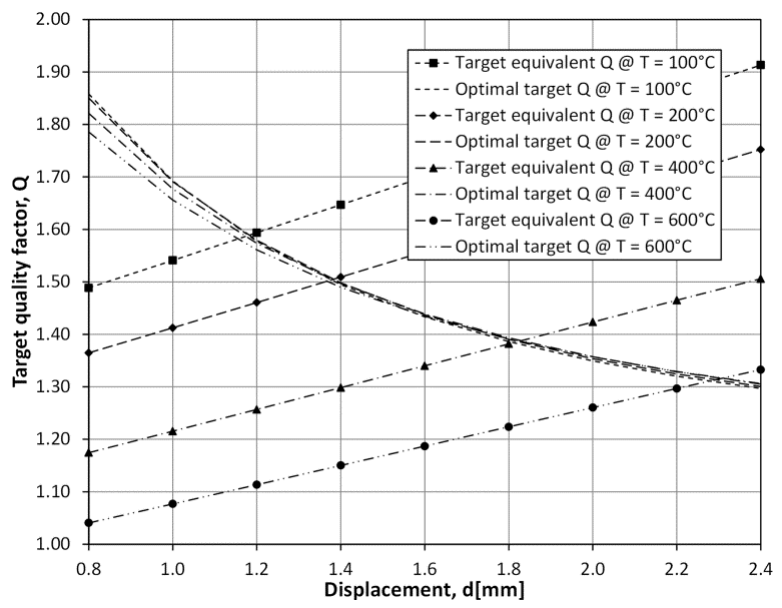

Fig. 7 Optimal and equivalent target quality factors at 1 $\mathrm{MHz}$.
For the AISI4140 target, $\mu_{\mathrm{r}} \approx 40, \frac{\left(\frac{\mathrm{d} \mu_{\mathrm{r}}}{\mu_{\mathrm{r}}}\right)}{\mathrm{dT}} \approx 0.2 \% /{ }^{\circ} \mathrm{C}$ and $\frac{\left(\frac{d R_{2}}{R_{2}}\right)}{d T}=\frac{\left(\frac{d \rho}{\rho}\right)}{d T} \approx 0.1 \% /{ }^{\circ} \mathrm{C}$ [7]. The $X_{M}$ and $L_{2}$ temperature sensitivities follow from (17) and (18) what equals approximately $0.005 \% /{ }^{\circ} \mathrm{C}$ for this material. The target resistance temperature sensitivity is about 20 times higher than the effective permeability sensitivity and therefore it is dominant in this case. Thus, in the following simulation only the influence of the target resistivity is considered.

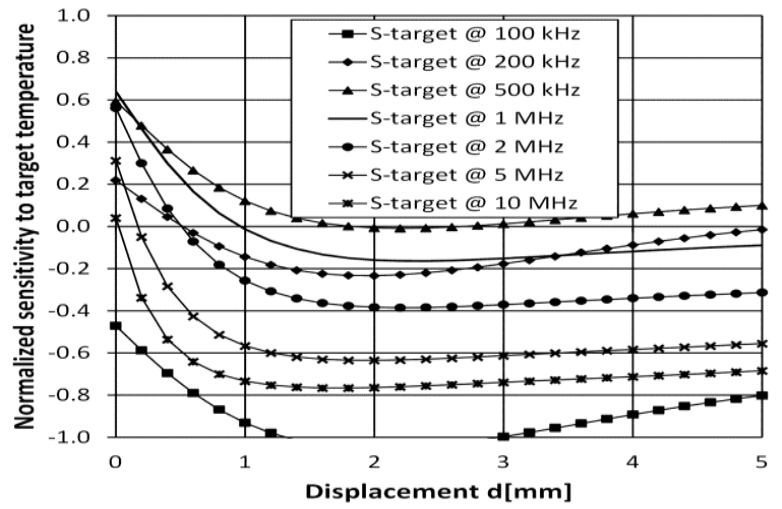

Fig. 8 Displacement dependence of normalized sensitivity to target temperature $\left(S_{R_{2}}^{Z_{\text {res }}}\right)$ at $20^{\circ} \mathrm{C}$ Frequency is the parameter.

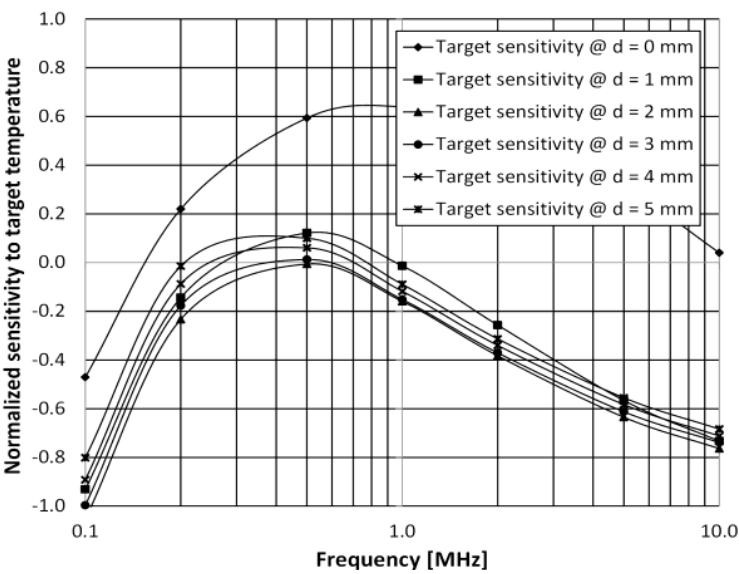

Fig. 9 Frequency dependence of normalized sensitivity to target temperature $\left(S_{R_{2}}^{Z_{\text {res }}}\right)$ at $20^{\circ} \mathrm{C}$. Displacement is the parameter.

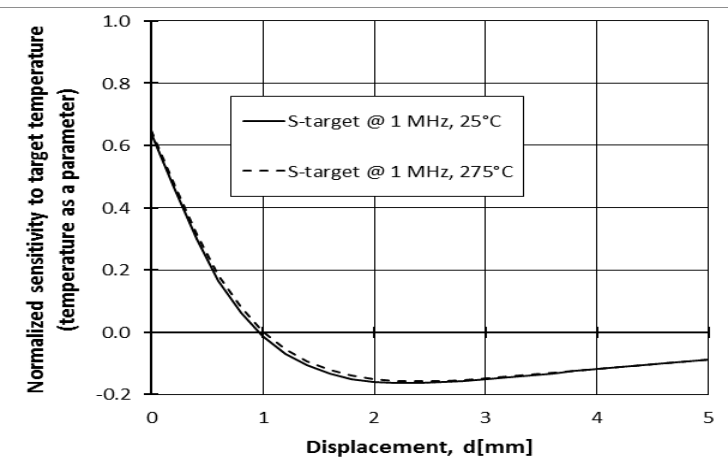

Fig. 10 Displacement dependence of normalized sensitivity to target temperature $\left(S \_\left(R \_2\right)^{\wedge}\left(Z \_r e s\right)\right)$ at $1 \mathrm{MHz}$. Temperature is the parameter. 


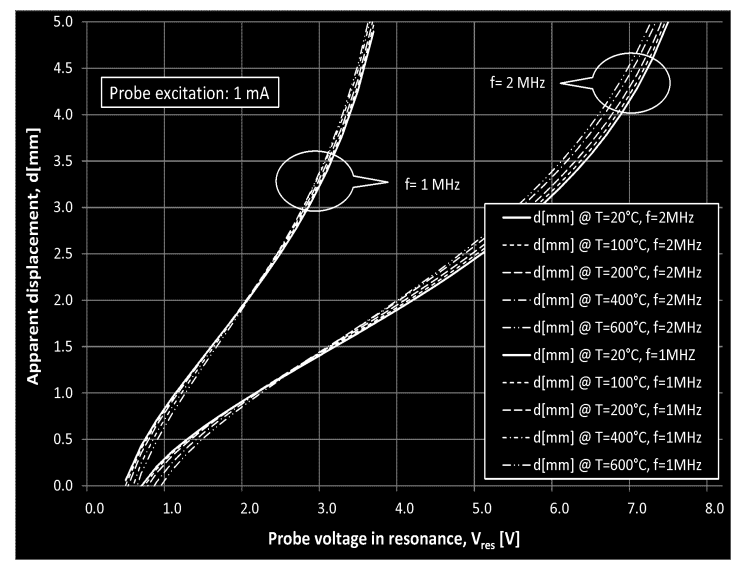

Fig. 11 Apparent displacement-probe voltage transfer curves at $1 \mathrm{MHz}$ and $2 \mathrm{MHz}$.

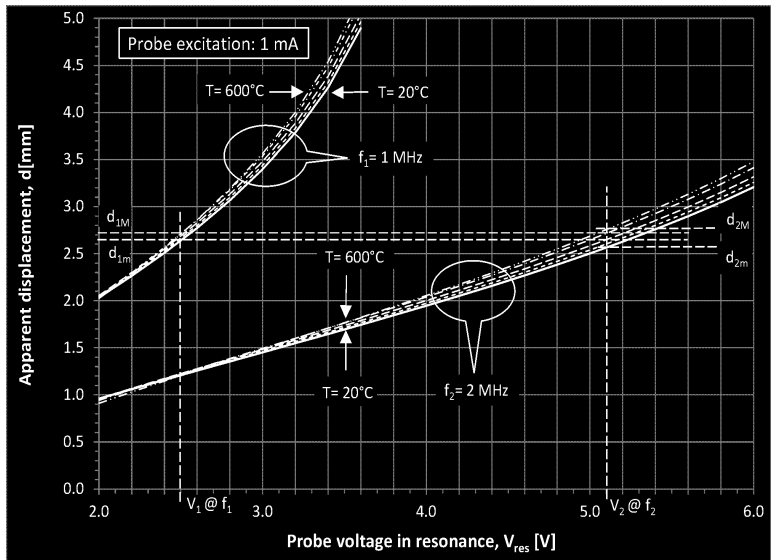

Fig. 12 Zoom-view of apparent displacement-probe voltage transfer curves at $1 \mathrm{MHz}$ and $2 \mathrm{MHz}$. In this example the probe voltage reading is $2.5 \mathrm{~V}$ at $1 \mathrm{MHz}$ and $5.1 \mathrm{~V}$ at $2 \mathrm{MHz}$.

\section{SIMULATION}

Experimental verification of the analysis results would require quite complicated test rig consisting of a precision slide table and controlled high temperature target heater, arranged in a manner where only the target would be heated while the probe would stay cool (how to guaranty that with the probe only few millimetres away from the hot target?). Therefore, instead of experimental verification, simulation was decided upon for the initial confirmation of the analysis, leaving the experiments for future work. All the simulation results to follow are for the "Probe No.2" [8], [9], [10]. The simulation model is the same as in [9] which validity is confirmed with probe voltage vs. displacement measurement reported in [9]. In Fig. 6 there is the set of apparent displacement-probe voltage transfer curves evaluated for target temperature range $20^{\circ} \mathrm{C}-600^{\circ} \mathrm{C}$. It is evident that there is a range of displacement values corresponding to each particular probe voltage. Therefore, there is ambiguity in measured displacement (over $\pm 0.3 \mathrm{~mm}$ or equivalently over $\pm 5 \%$ at the displacement range limits). Another problem is that the change of actual displacement can be completely masked by the target temperature change, making the measurement useless [6]. In Fig. 7 there are the optimal target quality factors $\left(Q_{2}^{\text {opt }}\right)$ for various displacements and temperatures calculated from (18), as well as, the equivalent target quality factors $\left(Q_{2}\right)$ derived by simulation [9]. Although $Q_{2}^{\text {opt }}$ doesn't change much with temperature, $Q_{2}$ changes considerably with both temperature and displacement. The ideal target temperature compensation would be achieved atpoints of intersection of optimal and equivalent target quality factor curves. Unfortunately, it is displacement dependent. The next step in search for optimum compensation is investigation of frequency influence. In Figs. 8 and 9 there are the simulation results for $\mathrm{S}_{\mathrm{R}_{2}}^{\mathrm{Z}_{\text {res }}}$ at $20^{\circ} \mathrm{C}$, but for varying frequency and displacement. In Fig. 8 there is the sensitivity versus displacement with frequency as a parameter, while in Fig. 9 there is the sensitivity versus frequency with displacement as a parameter. It is apparent that for this particular probe the operating frequency of $500 \mathrm{kHz}$ would be optimal. The resulting sensitivity is quite low, restricted to 0.1 over the $1 \mathrm{~mm}-5 \mathrm{~mm}$ range usually encountered in practice. Such a low sensitivity could be considered acceptable for industrial use. The frequency and displacement dependent differential sensitivities displayed in Figs. 8 and 9 are simulated for temperature of $20^{\circ} \mathrm{C}$. At other temperatures sensitivities will be different because all the parameters in (17) (except $\mathrm{R}_{1}$ ) vary with the target temperature. In Fig. 10 there is a simulation of $\mathrm{S}_{\mathrm{R}_{2}}^{\mathrm{Z}_{\text {res }}}$ at $1 \mathrm{MHz}$ for $\mathrm{T}=25^{\circ} \mathrm{C}$ and $\mathrm{T}=275^{\circ} \mathrm{C}$. It is evident that there is very little difference in sensitivity at rather very different temperatures. Thus, the optimum target temperature compensation will be also valid in a wide temperature range

TABLE I

Calibration Data At $1 \mathrm{MHz}$

\begin{tabular}{cccccc}
\hline \hline Voltage & \multicolumn{5}{c}{ Estimateddisplacement, $\mathrm{d}[\mathrm{mm}]$ at cal. } \\
$\mathrm{V}[\mathrm{V}]$ & $20^{\circ} \mathrm{C}$ & $100^{\circ} \mathrm{C}$ & $200^{\circ} \mathrm{C}$ & $400^{\circ} \mathrm{C}$ & $600^{\circ} \mathrm{C}$ \\
\hline 0.4 & 0.060 & 0.0070 & -0.0690 & - & -0.3910 \\
0.6 & 0.430 & 0.3990 & 0.3520 & 0.245 & 0.1330 \\
0.8 & 0.707 & 0.6850 & 0.6520 & 0.572 & 0.4850 \\
1.0 & 0.948 & 0.9340 & 0.9090 & 0.847 & 0.7750 \\
1.2 & 1.171 & 1.1640 & 1.1470 & 1.098 & 1.0370 \\
1.4 & 1.387 & 1.3840 & 1.3740 & 1.337 & 1.2860 \\
1.6 & 1.600 & 1.6020 & 1.5990 & 1.572 & 1.5290 \\
1.8 & 1.814 & 1.8220 & 1.8240 & 1.808 & 1.7740 \\
2.0 & 2.034 & 2.0470 & 2.0550 & 2.050 & 2.0240 \\
2.2 & 2.264 & 2.2810 & 2.2960 & 2.301 & 2.2850 \\
2.4 & 2.509 & 2.5310 & 2.5510 & 2.568 & 2.5610 \\
2.6 & 2.773 & 2.8000 & 2.8280 & 2.857 & 2.8600 \\
2.8 & 3.065 & 3.0980 & 3.1330 & 3.176 & 3.1900 \\
3.0 & 3.397 & 3.4370 & 3.4800 & 3.538 & 3.5640 \\
3.2 & 3.786 & 3.8330 & 3.8860 & 3.962 & 4.0030 \\
3.4 & 4.264 & 4.3200 & 4.3850 & 4.482 & 4.5420 \\
3.6 & 4.895 & 4.9620 & 5.0410 & 5.166 & 5.2480 \\
\hline \hline
\end{tabular}

TABLE II

Calibration Data AT $2 \mathrm{MHz}$

\begin{tabular}{crrrrr}
\hline Voltage & \multicolumn{5}{c}{ Estimated displacement, $d[\mathrm{~mm}$ ] at cal. temperatures } \\
$V[\mathrm{~V}]$ & $20^{\circ} \mathrm{C}$ & $100^{\circ} \mathrm{C}$ & \multicolumn{1}{c}{$200^{\circ} \mathrm{C}$} & $400^{\circ} \mathrm{C}$ & $600^{\circ} \mathrm{C}$ \\
\hline 0.0 & -1.23169 & -1.34483 & -1.49555 & -1.77505 & -2.01171 \\
0.2 & -0.69738 & -0.78036 & -0.89502 & -1.12035 & -1.32414 \\
0.4 & -0.29838 & -0.35722 & -0.44170 & -0.61769 & -0.78719 \\
0.6 & -0.00633 & -0.04674 & -0.10687 & -0.23977 & -0.37588 \\
0.8 & 0.20644 & 0.17978 & 0.13818 & 0.04070 & -0.06524 \\
1.0 & 0.36863 & 0.35099 & 0.32219 & 0.25100 & 0.16969
\end{tabular}


INTERNATIONAL JOURNAL OF INNOVATIVE RESEARCH IN ELECTRICAL, ELECTRONICS, INSTRUMENTATION AND CONTROL ENGINEERING Vol. 4, Issue 4, April 2016

\begin{tabular}{lllll}
0.50634 & 0.49437 & 0.47336 & 0.41843 & 0.35391 \\
0.63090 & 0.62346 & 0.60850 & 0.56516 & 0.51116 \\
0.74617 & 0.74257 & 0.73270 & 0.69896 & 0.65349 \\
0.85511 & 0.85487 & 0.84941 & 0.82387 & 0.78558 \\
0.95974 & 0.96253 & 0.96103 & 0.94279 & 0.91077 \\
1.06123 & 1.06681 & 1.06895 & 1.05739 & 1.03105 \\
1.16050 & 1.16870 & 1.17425 & 1.16892 & 1.14786 \\
1.25832 & 1.26901 & 1.27780 & 1.27835 & 1.26225 \\
1.35532 & 1.36840 & 1.38028 & 1.38645 & 1.37509 \\
1.45202 & 1.46740 & 1.48228 & 1.49388 & 1.48710 \\
1.54889 & 1.56652 & 1.58431 & 1.60120 & 1.59888 \\
1.64639 & 1.66622 & 1.68686 & 1.70895 & 1.71100 \\
1.74494 & 1.76695 & 1.79040 & 1.81763 & 1.82400 \\
1.84497 & 1.86913 & 1.89538 & 1.92771 & 1.93840 \\
1.94692 & 1.97322 & 2.00227 & 2.03970 & 2.05471 \\
2.05123 & 2.07969 & 2.11155 & 2.15410 & 2.17348 \\
2.15843 & 2.18906 & 2.22375 & 2.27149 & 2.29528 \\
2.26904 & 2.30187 & 2.33943 & 2.39245 & 2.42076 \\
2.38370 & 2.41877 & 2.45926 & 2.51767 & 2.55061 \\
2.50310 & 2.54046 & 2.58396 & 2.64793 & 2.68564 \\
2.62808 & 2.66780 & 2.71439 & 2.78411 & 2.82678 \\
2.75960 & 2.80177 & 2.85157 & 2.92726 & 2.97512 \\
2.89884 & 2.94355 & 2.99671 & 3.07867 & 3.13198 \\
3.04725 & 3.09464 & 3.15133 & 3.23989 & 3.29898 \\
3.20666 & 3.25686 & 3.31728 & 3.41286 & 3.47812 \\
3.37938 & 3.43258 & 3.49697 & 3.60008 & 3.67198 \\
3.56848 & 3.62490 & 3.69357 & 3.80481 & 3.88391 \\
3.77813 & 3.83801 & 3.91133 & 4.03142 & 4.11847 \\
4.01417 & 4.07784 & 4.15626 & 4.28612 & 4.38194 \\
4.28532 & 4.35314 & 4.43718 & 4.57791 & 4.68357 \\
4.60527 & 4.67764 & 4.76791 & 4.92092 & 5.03768 \\
4.99782 & 5.07491 & 5.17141 & 5.33589 & 5.46312 \\
5.49948 & 5.57788 & 5.67624 & 5.84513 & 5.97922 \\
\hline & & & & \\
& & &
\end{tabular}

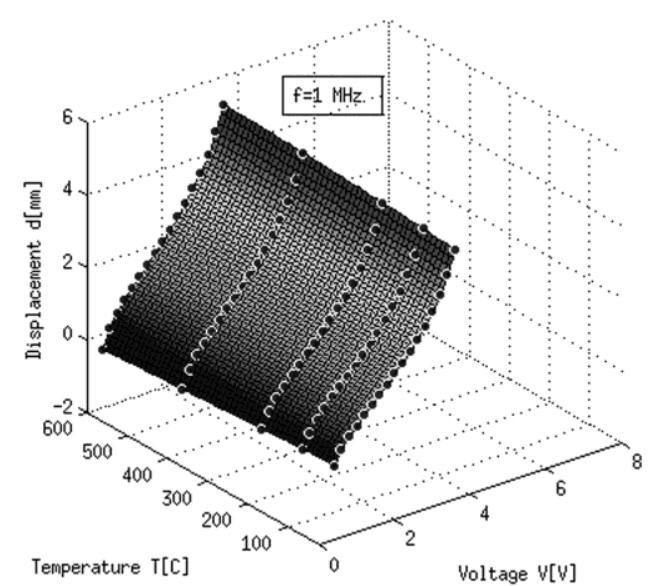

1.03105

14786

.26225

1.59888

1.71100

1.82400

2.17348

.42076

2.68564

2.82678

97512

3.13198

3.47812

3.67198

88391

3.38194

.68357 5.97922

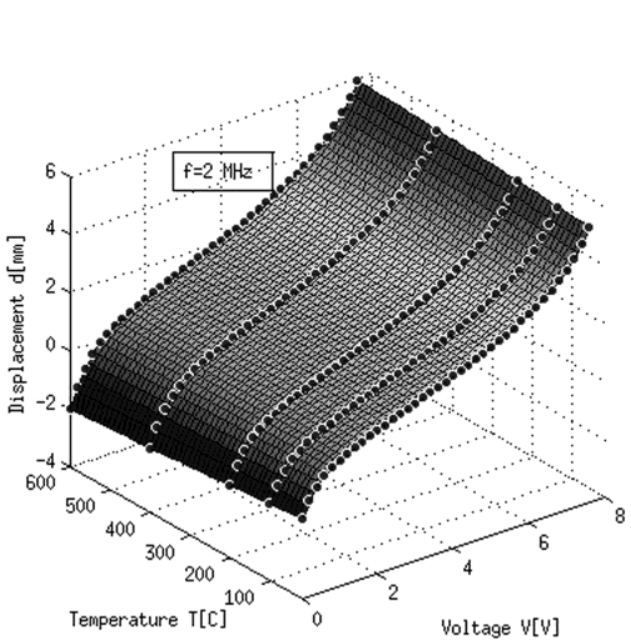

Fig. 13 Calibration functions at $1 \mathrm{MHz}$ and $2 \mathrm{MHz}$.

\section{DISPLACEMENT AND TEMPERATURE ESTIMATION}

The temperature dependence of displacement measurement raises the question whether it could be used for target temperature measurement, at least for acceptable estimate of it. Selecting the operating frequency for optimum sensitivity compensation would map the family of displacement-probe voltage transfer curves into (almost) one curve, removing most of the ambiguity from displacement measurement and narrowing the range of apparent displacement. Measurement at a frequency very different from the optimal one would result in a broader family of curves. If almost constant displacement could be presumed during these measurements (i.e. only slowly varying, like: rotor thrust position, rotor radial position on the oil film in the journal bearing, low-pass filtered vibration etc.), the narrow displacement range will limit the range of possible target temperatures. In Fig. 11 there are the transfer curves for two arbitrary frequencies (1 $\mathrm{MHz}$ and $2 \mathrm{MHz}$, none optimal!). The expanded view is in Fig. 12 clearly showing the range of possible target temperatures.

\section{A. Displacement Estimation}

If it is presumed that the target temperature is within calibration temperature limits $\mathrm{T}_{\mathrm{m}}=20^{\circ} \mathrm{C}$ and $\mathrm{T}_{\mathrm{M}}=600^{\circ} \mathrm{C}$ (where the simulation is evaluated), the corresponding displacement limits are $d_{1 \mathrm{~m}}, d_{1 \mathrm{M}}$ and $\mathrm{d}_{2 \mathrm{~m}}, \mathrm{~d}_{2 \mathrm{M}}$ at $\mathrm{f}_{1}=1 \mathrm{MHz}$ and $f_{2}=2 \mathrm{MHz}$, respectively. It is obvious that the minimum displacement $\left(\mathrm{d}_{\mathrm{m}}\right)$ cannot be smaller than the maximum one of $\mathrm{d}_{1 \mathrm{~m}}$ and $\mathrm{d}_{2 \mathrm{~m}}$, and the maximum displacement $\left(\mathrm{d}_{\mathrm{M}}\right)$ cannot be bigger than the minimum one of $\mathrm{d}_{1 \mathrm{M}}$ and $\mathrm{d}_{2 \mathrm{M}}$. In this example $\mathrm{d}_{\mathrm{m}}=\mathrm{d}_{1 \mathrm{~m}}$ and $\mathrm{d}_{\mathrm{M}}=\mathrm{d}_{1 \mathrm{M}}$, what by inspection of transfer curves at $f_{2}$ bounds the temperature between $200^{\circ} \mathrm{C}$ and $400^{\circ} \mathrm{C}$. This concept can be expanded to $\mathrm{N}$ frequencies, yielding

$$
\begin{aligned}
& \mathrm{d}_{\mathrm{m}}=\max _{\mathrm{i}=1 \ldots \mathrm{N}}\left(\mathrm{d}_{\mathrm{i}, \mathrm{m}}\right) \\
& \mathrm{d}_{\mathrm{M}}=\min _{\mathrm{i}=1 \ldots \mathrm{N}}\left(\mathrm{d}_{\mathrm{i}, \mathrm{M}}\right)
\end{aligned}
$$

For any arbitrary displacement it is reasonable to presume that at least one of many $(\mathrm{N})$ selected frequencies would be close to optimal, significantly narrowing the apparent displacement range and therefore making the displacement estimation closer to the real value. Two procedures for displacement estimation are investigated

Procedure A: Displacement estimation by averaging the averaged displacement estimation follows from averaging $\mathrm{d}_{\mathrm{m}}$ and $\mathrm{d}_{\mathrm{M}}$

$$
\mathrm{d}=\frac{\mathrm{d}_{\mathrm{m}}+\mathrm{d}_{\mathrm{M}}}{2} .
$$

Procedure B: Displacement estimation by interpolation upon estimation of target temperature at $d_{m}, d_{M}$ and $d$ by using one of the target temperature estimation methods (proposed in section B.), linear interpolation yields target temperature at averaged displacement estimation

$$
\mathrm{T}(\mathrm{d})=\mathrm{T}\left(\mathrm{d}_{\mathrm{m}}\right)+\frac{\mathrm{T}\left(\mathrm{d}_{\mathrm{M}}\right)-\mathrm{T}\left(\mathrm{d}_{\mathrm{m}}\right)}{\mathrm{d}_{\mathrm{M}}-\mathrm{d}_{\mathrm{m}}}\left(\mathrm{d}^{\prime}-\mathrm{d}_{\mathrm{m}}\right)
$$

where $\mathrm{d}^{\prime}$ is the interpolated displacement estimation (Fig.15). From (22) there follows the interpolated 
displacement estimation

$$
d^{\prime}=d_{m}+\frac{T(d)-T\left(d_{m}\right)}{T\left(d_{M}\right)-T\left(d_{m}\right)}\left(d_{M}-d_{m}\right) .
$$

B. Target Temperature Estimation

Mapping of probe voltage measurement or simulation data into displacement and temperature is usually done via a calibration table. The table itself is discrete, i.e. the voltage readings are in suitable size steps generating discrete sets of displacement and temperature data. Generally, the actual reading may not be found in the table but the adjacent lower and higher values. In this case some fitting procedure is needed. The calibration data are in Tables I and II for $\mathrm{f}=1 \mathrm{MHz}$ and $\mathrm{f}=2 \mathrm{MHz}$, respectively. The graphic display of calibration functions is in Fig. 13. The fitting procedures investigated here are:

1) Cubic spline interpolation (implemented in Mathcad)

a) Successive 1D-cubic splines (global fit mode fitting along all rows first, then fitting along the vector of rows fitting results). Full data in calibration matrix are used.

b) Successive 1D-cubic splines (local fit mode fitting along selected rows first, then fitting along the vector of rows fitting results). Used is a reduced set of data contained in a $5 \times 5$ square matrix, 5 total rows symmetrically enshroudingtherow(s) nearest to the row(s) corresponding to the measured votage, 5 columns corresponding to the calibration temperatures.

c) Successive 1D-cubic splines (global fit mode fitting along all columns first, then fitting along the vector of columns fitting results). Full data in calibration matrix is used.

d) 2D-cubic spline (local fit mode - 2D multivariate fit of reduced data set as in the method 1b). Comment: square matrix is required by Mathcad!

e) Bicubic spline (global fit mode - bicubic 2D multivariate fit of full data set)

f) Bicubic spline (local fit mode - bicubic 2D multivariate fit of reduced data set as in the method $1 b$ ).

2) Polynomial regression (implemented in Mathcad)

a) 2D-cubic polynom regression (global fit mode $-2 \mathrm{D}$ multivariate regression of full data set)

b) 2D-cubic polynom regression (local fit mode $-2 \mathrm{D}$ multivariate regression fit of reduced data set as in the method $1 \mathrm{~b}$ )

c) 2D-adaptive quadratic polynom regression (global fit mode $-2 \mathrm{D}$ multivariate regression fit of full data set)

d) 2D-adaptive quadratic polynom regression (local fit mode $-2 \mathrm{D}$ multivariate regression fit of reduced data set as in the method $1 \mathrm{~b}$ )

3) Spline root-finding (implemented in Matlab)

a) Bisection root-finding method (global fit mode search for root(s) of full data set bicubic spline)

b) Bisection root-finding method (local fit mode search for root(s) of reduced data set bicubic spline as in the method $1 \mathrm{~b}$ )

4) Artificial Neural Network (ANN) regresion (implemented in Microsoft Azure Machine Learning) a) ANN regression (global fit mode - full data set, distributed $70 \%$ in training set and $30 \%$ in validation set, 1 hidden layer, 18 neurons in the hidden layer)

b) $\quad$ ANN regression (local fit mode - reduced data set as in the method $1 \mathrm{~b}$ ), distributed $70 \%$ in training set and $30 \%$ in validation set, 1 hidden layer, 18 neurons in the hidden layer.

TABLE III

TARGET TEMPERATURE AND DisPlaCEMENT Estimation

\begin{tabular}{|c|c|c|c|c|c|c|c|}
\hline \multirow[b]{2}{*}{ Method } & \multirow{2}{*}{$\begin{array}{c}d_{m} \\
{[\mathrm{~mm}]} \\
2.641\end{array}$} & \multirow{2}{*}{$\begin{array}{c}d \\
{[\mathrm{~mm}]} \\
2.676\end{array}$} & \multirow{2}{*}{$\begin{array}{c}d_{M} \\
{[\mathrm{~mm}]} \\
2.711\end{array}$} & \multirow[b]{2}{*}{ Decision } & \multicolumn{3}{|c|}{ Linearinterpolation } \\
\hline & & & & & $\begin{array}{c}T^{\prime} \\
{\left[{ }^{\circ} \mathrm{C}\right]}\end{array}$ & $\begin{array}{c}d^{\prime} \\
{[\mathrm{mm}]}\end{array}$ & $\begin{array}{c}\Delta d \\
{[\mu \mathrm{m}]}\end{array}$ \\
\hline 1a) & 563.96 & 711.35 & 895.21 & reject & & & \\
\hline 1b) & 136.89 & 213.67 & 429.38 & reject & & & \\
\hline 1c) & 182.93 & 268.83 & 383.24 & accept & 283.09 & 2.671 & -4.982 \\
\hline 1d) & 182.51 & 271.76 & 384.10 & accept & 283.31 & 2.672 & -4.009 \\
\hline 1e) & 182.56 & 271.31 & 383.75 & accept & 283.16 & 2.672 & -4.121 \\
\hline 1f) & 182.76 & 271.55 & 383.86 & accept & 283.31 & 2.672 & -4.093 \\
\hline $2 a)$ & 354.94 & 449.10 & 562.18 & reject & & & \\
\hline $2 b)$ & 183.38 & 274.18 & 383.92 & accept & 283.65 & 2.673 & -3.306 \\
\hline 2c) & 195.04 & 277.58 & 372.82 & accept & 283.93 & 2.673 & -2.500 \\
\hline 2d) & 182.78 & 273.88 & 384.54 & accept & 283.66 & 2.673 & -3.393 \\
\hline 3a) & 181.57 & 276.97 & 384.98 & accept & 283.28 & 2.674 & -2.170 \\
\hline $3 b)$ & 231.22 & 282.52 & 339.68 & accept & 285.45 & 2.674 & -1.891 \\
\hline 4a) & 202.60 & 299.81 & 397.96 & accept & 300.28 & 2.676 & -0.168 \\
\hline 4b) & 187.29 & 296.58 & 407.39 & accept & 297.34 & 2.676 & -0.242 \\
\hline $\begin{array}{c}\text { Avg } \\
{\left[{ }^{\circ} \mathrm{C}\right]:}\end{array}$ & 190.42 & 278.63 & 382.39 & Avg: & 286.40 & 2.673 & -2.807 \\
\hline $\begin{array}{l}\text { StDev } \\
{\left[{ }^{\circ} \mathrm{C}\right]:}\end{array}$ & 14.36 & 9.90 & 15.97 & StDev: & 5.91 & 0.002 & 1.508 \\
\hline $\begin{array}{r} \pm \text { Conf } \\
{\left[{ }^{\circ} \mathrm{C}\right]:}\end{array}$ & 9.65 & 6.65 & 10.73 & \pm Conf: & 3.97 & 0.001 & 1.013 \\
\hline \pm Error: & $5.07 \%$ & $2.39 \%$ & $2.81 \%$ & \pm Error: & $1.39 \%$ & $0.04 \%$ & \\
\hline
\end{tabular}

Legend: $\quad$ Conf $=$ Confidence interval $(95 \%$ Confidence, $\mathrm{t}$-distribution $)$ Error $=$ Confidence interval/Average $(\%)$

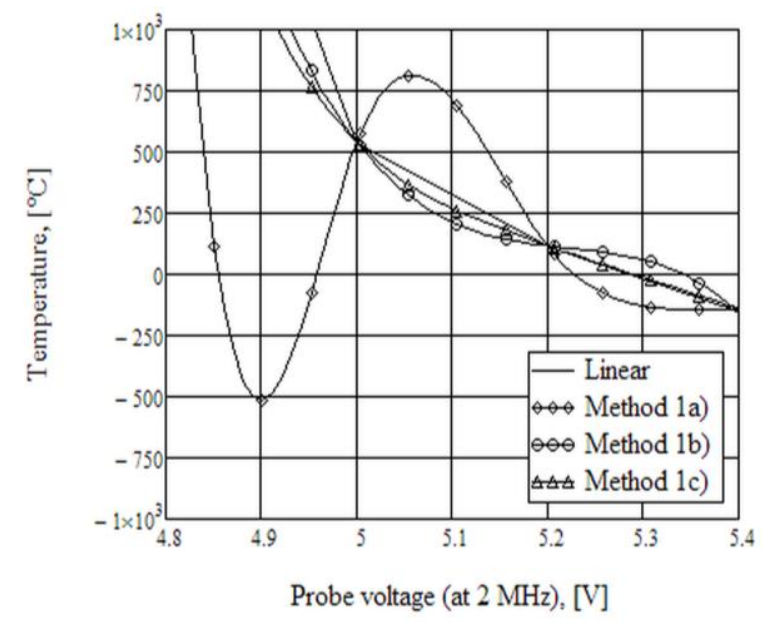

Fig. 14 Spline behaviour at $d$ for different interpolation methods

\section{EXAMPLE OF DISPLACEMENT AND TEMPERATURE ESTIMATION}

Here we present an example of displacement and temperature estimation. It is assumed that the probe is placed at constant displacement from the heated target. The probe voltage is measured at $1 \mathrm{MHz}$ and $2 \mathrm{MHz}$ and 
the readings are $\mathrm{V}_{1}=2.5 \mathrm{~V}$ and $\mathrm{V}_{2}=5.1 \mathrm{~V}$, respectively. The displacement and the temperature are to be estimated by two procedures using the methods described. inspection of Table I, we get the following bounds:

$\mathrm{V}_{1 \mathrm{~L}}=2.4 \mathrm{~V}: \mathrm{d}_{1 \mathrm{Lm}}=2.509 \mathrm{~mm}, \mathrm{~d}_{1 \mathrm{LM}}=2.561 \mathrm{~mm}$ $\mathrm{V}_{1 \mathrm{H}}=2.6 \mathrm{~V}: \mathrm{d}_{1 \mathrm{Hm}}=2.773 \mathrm{~mm}, \mathrm{~d}_{1 \mathrm{HM}}=2.869 \mathrm{~mm}$

By inspection of Figs. 11, 12 and 13, we guess the change of $\mathrm{d}$ versus $\mathrm{V}$ to be almost linear in the voltage range $2.4 \mathrm{~V}$ $-2.6 \mathrm{~V}$. Therefore, by averaging $\left(\mathrm{d}_{1 \mathrm{Lm}}, \mathrm{d}_{1 \mathrm{Hm}}\right)$ and $\left(\mathrm{d}_{1 \mathrm{LM}}\right.$, $\mathrm{d}_{1 \mathrm{HM}}$ ) there follow $\mathrm{d}_{1 \mathrm{~m}}=2.641 \mathrm{~mm}$ and $\mathrm{d}_{1 \mathrm{M}}=2.711 \mathrm{~mm}$, respectively. By inspection of Tables I and II and application of (19), (20), and (21) we get averaged displacement estimation, $\mathrm{d}=2.676 \mathrm{~mm} \square \square$ The temperature estimation follows from application of adopted interpolation and regression methods to $d_{m}, d$ and $d_{M}$ and data in Table II. The results are summarized in Table III. Here are the comments on results:

Procedure A: There is a good grouping of results for almost all of the methods, except for the methods 1a), 1b) and 2a) which are therefore rejected. Methods 1a) and 1b) employ cubic spline interpolation which is by definition good for interpolation only and not for extrapolation! By inspection of Table II it is evident that the estimated $d_{m}, d$ and $\mathrm{d}_{\mathrm{M}}$ are not in the bounds of calibration temperatures for most of the probe voltage readings (matrix rows). For these rows cubic spline actually extrapolates with catastrophic errors! Therefore, interpolation along these rows is not applicable. Although the discrepancy for the method 1b) is much smaller than for 1a) it is still too big. Method 1b) performs cubic spline interpolation along the reduced data set of the rows where displacement is within the bounds of calibration. The error is then not caused by extrapolation, but by missing influence of data far from the selected rows. Behaviour of splines for $d=2.676 \mathrm{~mm}$ is in Fig. 14. It is evident that the big error for the method 1a) is due to the wild swing of the corresponding spline.

Methods 4a) and 4b) employ Artificial Neural Network (ANN) regression for full and reduced (as in method 1b) data sets, respectively. The results are somewhat higher than for other methods, but still acceptable. Further tweaking the ANN in the sense of different distribution of data among the training and validation sets, number of hidden layers, number of neurons etc. may possibly provide better results.

Procedure B: The right hand side of Table III contain results obtained by averaging $T\left(d_{m}\right)$ and $T\left(d_{M}\right)$ for $T^{\prime}(d)$ and by linear interpolation for $\mathrm{d}^{\prime}$ according to (23) and Fig. 15. The results are very consistent for all the accepted methods, but are somewhat offset from the results of Procedure A. For the selected probe voltage reading in this example $(\mathrm{V}=5.1 \mathrm{~V})$, the calibration curves are mildly concave (Fig. 12) and the linear interpolation yields higher temperature than for the selected fitting method. For a voltage reading less than approximately $2.5 \mathrm{~V}$ the calibration curves are convex and the linear interpolation would yield lower temperature. Decision which estimate to accept (fitted or interpolated) is dependent on which part of the calibration curve (convex or concave) corresponds to the voltage reading. However, the difference is, depending on the method used, limited to $\square \mathrm{T}<15^{\circ} \mathrm{C}$, what is less than $5 \%$ of average. The estimated displacement difference is limited to $\square \mathrm{d}<5 \square \mathrm{m}$ what can be considered negligible.

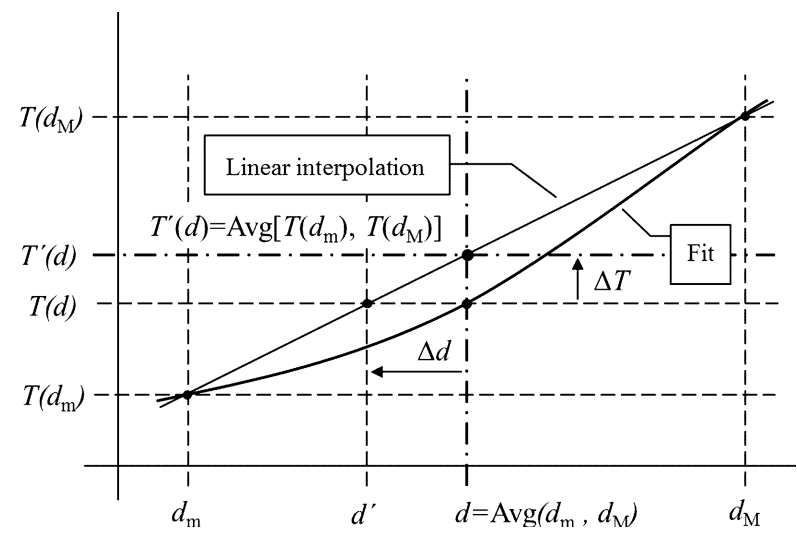

Fig.15 Visualization of Procedure A and Procedure B

\section{CONCLUSION}

The effect of target temperature variation on eddy current displacement sensing is modelled, analysed and evaluated by simulation. The equivalent target quality factor is detected as the main factor that along with the probe equivalent quality factor determine the effect. This effect manifests in ambiguity of displacement measurement, as well as, masking the displacement variation by target temperature variation, and vice versa. This is all due to the sensitivity of the probe impedance to the target temperature. The analysis and the simulation show that there is an optimal, only mildly temperature dependent, operating frequency for minimum sensitivity over an acceptable displacement range. Minimization of the sensitivity will automatically reduce the displacement ambiguity and possible masking, as well.

Displacement and target temperature estimation can be done by interpolation/ regression at two (or more) distinct operating frequencies. One frequency should be selected as close as possible to the optimal one in order to narrow the range of apparent displacement, while the other(s) should be selected for maximum temperature dependence in order to narrow the range of possible temperatures. By careful selection of estimation procedure and interpolation/regression method, the target temperature can be estimated quite well. The example presented, shows the variation of the estimated temperature by applying Procedure A with the methods used to be within $\pm 2.39 \%$ of average at estimated displacement, while applying the Procedure B it is even smaller $(( \pm 1.39 \%)$ The difference between procedures is less than $5 \%$ of average. The displacement variation is less than $5 \square \mathrm{m}$, what can be considered negligible.

\section{REFERENCES}

[1] Dowell, M.,Sylvester, G.,Krupp, R.,Zipfel, G., "Progress in turbomachinery prognostics and health management via eddycurrent sensing", Aerospace Conference Proceedings, 2000 IEEE, Volume: 6, Publication Year: 2000, Page(s): 133 - 143.

[2] GE Measurement \& Control, Proximity probes, available online:http://www.ge-mcs.com/en/bently-nevada-sensors-andtransducers/proximity-probes.html 
[3] A. G. Sheard, S. G. O’Donnell,J. F. Stringfellow, "High Temperature Proximity Measurement in Aero and Industrial Turbomachinery", J. Eng. Gas Turbines Power 121(1), Page(s): 167-173 (Jan 01, 1999)

[4] R.M.Masters, "Technique for Temperature Compensation of EddyCurrent Proximity Probes", NASA Technical Paper 2880, NASA Administration, Lewis Research Center, Cleveland, USA, 1989.

[5] Y.Lai, EddyCurrent Displacement Sensor with LTCC Technology, PhD Thesis, University of Freiburg, Germany, 2005.

[6] Lv Yunteng, Zhu Changsheng, "Research on the feasibility of eddy current displacement sensor with temperature variation for nonferromagnetic detection material", Electronic Measurement \& Instruments (ICEMI), 2013 IEEE 11th International Conference on, Volume:1, Publication Year: 2013, Page(s): 125 - 128.

[7] eFunda Inc., AISI4140 Steel properties, available online: http://www.efunda.com/materials/alloys/alloy_steels/show_alloy.cf $\mathrm{m}$ ?ID=AISI_4140\&show_prop=elec\&Page_Title=Alloy\%20Steel\% 20AISI\% 204140

[8] Vyroubal, D., Zele, D., "Experimental optimization of the probe for eddy-current displacement transducer", Instrumentation and Measurement, IEEE Transactions on, Volume: 42, Issue: 6, Publication Year: 1993, Page(s): 995 - 1000.

[9] Vyroubal, D., "Impedance of the eddy-current displacement probe: the transformer model", Instrumentation and Measurement, IEEE Transactions on, Volume: 53, Issue: 2, Publication Year: 2004, Page(s): $384-391$.

[10] Vyroubal, D., "Eddy-Current Displacement Transducer With Extended Linear Range and Automatic Tuning", Instrumentation and Measurement, IEEE Transactions on, Volume: 58, Issue: 9, Publication Year: 2009, Page(s): 3221 - 3231.

[11] D. Vyroubal and I. Lacković, „Target Temperature Effect on Eddy Current Displacement Sensing", in Proc. SAS2015 IEEE Sensors Appl. Symp., Zadar, Croatia, April 13-15, 2015, Page(s): 305-309.

[12] Pereira, J.M., Silva Girao, P.M.B., Postolache, O, „Fitting Transducer Characteristics to Measured Data", IEEE Instrumentation \& Measurement Magazine, Vol:4, Issue:4, December 2001, Page(s): 26-39.

[13] Mathcad 15.0/ Help/E-books/ Data Analysis Extension Pack, PTC Inc., Needham, Massachusetts, USA.

[14] Matlab R2013b / Curve Fitting Tool Help / (C) 1994-2015 The MathWorks, Inc.

[15]https://studio.azureml.net/Home/ViewWorkspace/UserIDWorkspace

\section{BIOGRAPHIES}

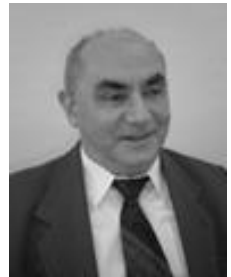

Darko Vyroubal (M'96) was born in Croatia in 1948. He received the B.S., M.S. and Ph.D. degrees in electronic instrumentation from the University of Zagreb, Croatia in 1970, 1974 and 1985, respectively. He was employed in the industry from 1970 till 1998. Since 1998 he is with the Karlovac University of Applied Sciences, Karlovac, Croatia where he is currently Professor. He also served as the Vice-Dean for 15 years. His research interest is in sensors and electronic instrumentation applied to power machinery.

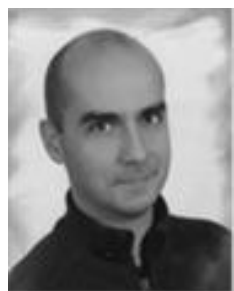

Vedran Vyroubal ( $\left.\mathrm{M}^{\prime} 00\right)$ was born in Croatia in 1977. He received the B.S. and M.S. degrees in electronic engineering from the University of Zagreb, Croatia in 2002 and 2011, respectively. He is currently persuing Ph.D. degree in electronic engineering. He was employed in the industry from 2002 till 2012. Since 2012 he is with the Karlovac University of Applied Sciences, Karlovac, Croatia where he is currently Lecturer. His research interest is in Internet of Things, multi agent systems and sensor fusion.

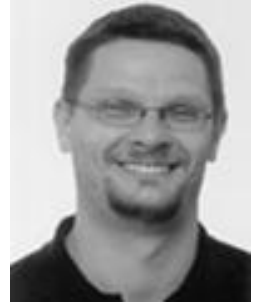

Adam Stančić was born in Croatia in 1972. He received the B.S. degree and $\mathrm{PhD}$ degree in Intelligent Transportation Systems from the University of Zagreb, Croatia in 2005 and 2013, respectively. $\mathrm{He}$ was employed in the industry from 2000 till 2015. Since 2015 he is with the Karlovac University of Applied Sciences, Karlovac, Croatia where he is currently Lecturer. His research interest is in machine learning and digital image analysis. 